\title{
AVALIAÇÃO DA IMPLEMENTAÇÃo DO DEPOIMENTO ESPECIAL: CONSTRUÇÃO DE UM INSTRUMENTO
}

Cátula da Luz Pelisoli

Tribunal de Justiça do Estado do Rio Grande do Sul

Débora Dalbosco Dell'Aglio

Universidade Federal do Rio Grande do Sul e Universidade La Salle
Recebido em: 15/07/2020

$1^{\text {a }}$ revisão em: $12 / 05 / 2020$ Aceito em: 23/05/2020

\section{RESUMO}

O Depoimento Especial - DE tornou-se o procedimento padrão de oitiva de crianças e adolescentes vítimas e testemunhas de violência no Brasil. Este trabalho objetivou a construção de um instrumento para a avaliação das condições de implementação do $D E$, a partir de quatro etapas: Na etapa 1 foi realizado um estudo qualitativo, para conhecer os aspectos que possibilitam e que dificultam a efetivação do $D E$, por meio de um questionário online respondido por 36 entrevistadores forenses brasileiros; $\mathrm{Na}$ etapa 2 construíram-se os itens do instrumento, com base na literatura e nos conteúdos previamente emergidos; $\mathrm{Na}$ etapa 3 ocorreu a estruturação e organização do instrumento; e na etapa 4, o conteúdo foi avaliado por dois juízes com ampla experiência prática e teórica. Essas etapas possibilitaram a qualificação e adequação do instrumento para avaliar as condições de realização do DE na realidade brasileira e pode contribuir para seu processo de implementação.

Palavras-chave: depoimento especial; psicologia jurídica; violência contra crianças e adolescentes. 


\section{EVALUATION OF THE IMPLEMENTATION OF THE SPECIAL TESTIMONY: CONSTRUCTION OF AN INSTRUMENT}

\section{ABSTRACT}

The Special Testimony - ST became the standard procedure for hearing children and adolescents victims and witnesses of violence in Brazil. This work aimed to construct an instrument for the evaluation of the conditions for the implementation of ST from four stages. In step 1, a qualitative study was carried out to know the aspects that enable and hinder the implementation through a questionnaire answered online by 36 Brazilian forensic interviewers. In stage 2 the instrument items were constructed, based on the literature and contents previously emerged; Step 3 refers to the structuring and organization of the instrument; and in step 4 the content evaluation was carried out by two judges with extensive practical and theoretical experience. These steps allowed the qualification and adequacy of the instrument to evaluate the conditions for performing the ST in Brazil and may contribute to the implementation.

Keywords: special testimony; forensic psychology; violence against children and adolescents

\section{EVALUACIÓN DE LA IMPLEMENTACIÓN DEL TESTIMONIO ESPECIAL: CONSTRUCCIÓN DE UN INSTRUMENTO}

\section{RESUMEN}

El Testimonio Especial - TE se ha convertido en el procedimiento estándar para escuchar a niños y adolescentes víctimas y testigos de violencia en Brasil. El objetivo de este trabajo fue construir un instrumento para la evaluación de las condiciones para la implementación de TE a partir de cuatro etapas: En el paso 1, se realizó un estudio cualitativo para conocer los aspectos que permiten y dificultan la implementación a través de un cuestionario respondido en línea por 36 entrevistadores forenses. La etapa 2 se construyeron los ítems del instrumento, basada en la literatura y en contenidos surgidos anteriormente. En paso 3 el instrumento fue estructurado y organizado; y en el paso 4, el contenido fue evaluado por dos jueces con amplia experiencia práctica y teórica. Estos pasos permitieron la calificación y idoneidad del instrumento para evaluar las condiciones para realizar el TE en Brasil y pueden contribuir a implementación.

Palabras clave: testimonio especial; psicología legal; violencia contra niños y adolescentes. 


\section{INTRODUÇÃO}

Há vários anos o Depoimento Especial - DE vem sendo discutido por profissionais das áreas do Direito, Serviço Social e Psicologia, que abordam aspectos favoráveis e desfavoráveis deste procedimento de oitiva de crianças e adolescentes e também de aspectos técnicos (Brito \& Parente, 2012). Mesmo diante de tantos debates, a Lei 13.431/2017 tornou o DE o procedimento padrão para a produção de prova judicial em situações em que crianças e adolescentes são vítimas ou testemunhas de violência no Brasil (Brasil, 2017) e o Decreto 9.603/2018 buscou sistematizar este procedimento, oferecendo algumas diretrizes mais específicas sobre como deve funcionar o DE no sistema de garantia de direitos (Brasil, 2018). No DE, a criança/adolescente deve ser ouvida em sala "reservada, silenciosa, com decoração acolhedora e simples" por profissional especializado, sendo este depoimento transmitido para a sala de audiências em tempo real. $O$ depoimento é gravado em áudio e vídeo e, como propõe a legislação, deve ser realizado o mais breve possível, considerando o período da violência sofrida/testemunhada. Em termos legais, o DE pode ocorrer em sede de antecipação de prova, o que significa que poderá ser determinado antes mesmo de a denúncia ser oferecida pelo Ministério Público ao Poder Judiciário.

O DE envolve uma mudança de paradigma para o Sistema de Justiça, que é historicamente fundamentado numa hierarquia bastante cristalizada e naturalizada pelas pessoas que o compõem. Em um processo judicial típico e em audiência tradicional, a lógica presidencial é muito bem evidenciada, seja pela posição que o Magistrado ocupa no espaço físico, seja por sua condução do evento. Tradicionalmente, os questionamentos realizados nos depoimentos tomados são feitos por meio de uma lógica confirmatória e objetiva, em que apenas interessam os esclarecimentos pontuais sobre determinados fatos. Como exemplo, pode-se citar uma vítima adulta, que ao entrar na sala de audiências e apresentar seu nome, ouvirá a leitura da denúncia. Neste momento, o crime do qual foi vítima é lido para que ela possa confirmar se vivenciou ou não aquela determinada violência. Assim, aquilo que ela vivenciou, muitas vezes como algo tão íntimo e devastador, é ali lido diante daquele público, de maneira formal e distante, com vistas à tomada de decisão que naquela ação se faz necessária. Até que se falasse sobre a necessidade de se ouvir de forma diferente as crianças e adolescentes (Dobke, 2001), milhares delas passaram por audiências tradicionais no Brasil, sendo questionadas de forma despreparada e inadequada, o que infelizmente, deve ainda ocorrer muitas vezes no país, mesmo na vigência da lei. Segundo Potter (2010), o caminho a ser percorrido pela vítima é "tortuoso, perverso e vitimizador" (p. 171) e as inadequadas intervenções do estado produzem revitimização, tendo efeitos tanto sobre a vítima quanto sobre a confiabilidade da prova produzida.

A mudança de paradigma na forma de realização da escuta/oitiva da criança, portanto, refere-se a um novo posicionamento das estruturas e papéis dos operadores do Direito, que diante de um DE de uma criança ou adolescente, precisa se transformar. Tanto a Lei quanto o Decreto tiveram que dar algumas garantias tanto ao entrevistador quanto à própria criança/adolescente 
vítima/testemunha, porque considerando os lugares de poder que esses ocupam, poderia ocorrer uma subjugação às determinações daqueles que protagonizam o Sistema de Justiça. Exemplo disso é quando esses documentos asseguram o direito de a criança/adolescente permanecer em silêncio ou quando garantem ao profissional autonomia para a adaptação de perguntas dos operadores do Direito para melhor compreensão pela criança/adolescente (Brasil, 2017; 2018). Dessa forma, a razão de ser do DE está justamente na escuta da criança em seu relato livre e na utilização de conhecimentos técnicos dos profissionais para evitar a revitimização, a violência institucional, ou seja, em proteger a criança. Mesmo assim, e exatamente pela característica hierárquica do Sistema de Justiça brasileiro, é necessário que a legislação defina certos procedimentos, para que no cotidiano dos depoimentos reais que são conduzidos, estes atores que detêm menos poder dentro deste Sistema (crianças/adolescentes e entrevistadores) possam ter respeitadas suas vontades e conhecimentos.

Foi ao se deparar com os limites do Direito na oitiva de crianças que Dobke (2001) denunciou a violência institucional que o Sistema de Justiça impunha a suas vítimas e testemunhas menores de idade. Reconhecendo as restrições da própria disciplina, Daltoe Cezar (2007) propôs o então chamado Depoimento Sem Dano, nomeado no ano de 2010 como Depoimento Especial (Conselho Nacional de Justiça, 2010). Ao trazer o conhecimento e a atuação de outras disciplinas para o contexto formal de uma audiência, uma série de transformações foram desencadeadas, não apenas em questões práticas daquele procedimento específico, mas do próprio lugar que o Direito ocupa. Desde então, tem sido necessário conhecer como estas práticas têm ocorrido no país.

Neste sentido, para conhecer como estão ocorrendo os DE's pelo Brasil, foi conduzido um estudo que buscou, através de profissionais atuantes neste procedimento, suas percepções e experiências. Uma pesquisa envolvendo 20 profissionais, incluindo Defensores públicos, Promotores de Justiça, Juízes e Psicólogas judiciárias, identificou que a autonomia do entrevistador dependia dos operadores do Direito com quem ele trabalhava. Neste estudo, observou-se que a autonomia do profissional variava de nula a total, sendo que a autonomia nula seria quando o profissional apenas transmite as questões dos operadores, sem possibilidade de nenhuma adaptação. Alguns participantes indicaram que o entrevistador tinha uma autonomia limitada, em que ele poderia adaptar a questão, mas precisaria obter o conteúdo que lhe foi solicitado. E por fim, alguns outros participantes, indicaram que o entrevistador teria autonomia irrestrita (Pelisoli \& Dell'Aglio, 2016). Em estudo mais recente, os autores encontraram que os participantes, que eram psicólogos entrevistadores, indicaram ter conquistado a autonomia necessária, sendo que em alguns casos apontaram haver maior rigidez por parte dos operadores do Direito. Outros resultados deste estudo apontam que esses profissionais buscam oferecer um contexto de continência e acolhimento, promovendo um atendimento adequado à faixa etária da vítima. Os entrevistadores fazem uso de protocolos de entrevista, para o que eles devem receber capacitação específica. A relação satisfatória entre o entrevistador e os 
profissionais do Direito também foi indicada como essencial para a realização do DE (Sanson \& Von Hohendorff, 2021).

Nos últimos anos, observa-se o investimento de tribunais brasileiros e também de profissionais autônomos e pesquisadores em obter qualificações para entrevista forense de crianças e adolescentes, assim como desenvolvimento de protocolos de entrevista, tema sobre o qual há poucos anos praticamente nada se falava no Brasil (Alves Júnior, 2013; Aznar-Blefari \& Padilha, 2015). Entrevistas baseadas em fontes de informação científica não podem ser substituídas por tentativas amadoras de ouvir a vítima, ainda que a pessoa que a realiza esteja bem intencionada (Santos, Gonçalves, Vasconcelos, Barbieri. \& Viana, 2014). O Protocolo NICHD -National Institute of Child Health and Human Development (Williams, Hackbarth, Blefari, Padilha \& Peixoto, 2014) e o Protocolo Brasileiro de Entrevista Forense (Childhood Brasil, Conselho Nacional de Justiça, Funda das Nações Unidas para a Infância \& National Children's Advocacy Center, 2020) são exemplos dos esforços em oferecer aos entrevistadores um guia seguro de como realizar essas entrevistas de uma forma protetiva e que maximize a qualidade e a quantidade de informação obtida.

Assim, percebe-se um avanço significativo tanto no sentido acadêmico quanto prático, considerando a necessidade de efetivação da lei. Observam-se movimentos de qualificação de profissionais entrevistadores no Brasil, ainda que esses possam não ser suficientes para dar conta da grande demanda, considerando que a violência contra crianças e adolescentes é um problema de saúde pública, que atinge milhares de crianças anualmente no Brasil. Já o investimento na qualificação de operadores do Direito neste tema é bastante incipiente. Segundo Roque e colaboradores (2014), os magistrados ainda estão despreparados para a escuta de crianças e adolescentes. $O$ estudo dos autores mostra que estes fazem uso de modelos instintivos e de práticas improvisadas, não se apropriando de estruturas metodológicas necessárias para o procedimento. A Resolução 299/2019 do Conselho Nacional de Justiça, considerando esta realidade, definiu sobre a necessidade de investimentos nessa área, que contemplam tanto a implantação de salas especiais em todas as comarcas brasileiras quanto a obrigatoriedade da qualificação de magistrados e profissionais que trabalham no DE (CNJ, 2019). Como problema complexo, a questão da violência contra crianças e adolescentes requer a intervenção de múltiplas disciplinas e no DE essa interação ocorre de maneira simultânea. Ainda que a criança tenha a sua frente apenas a presença do entrevistador, ela é informada de que os operadores do Direito a assistem e the transmitem questões. Este campo requer, portanto, a relação interdisciplinar, entre saberes.

Diante dessa complexidade que se impõe ao DE e aos profissionais que nele atuam, não se pode restringir o entendimento sobre a eficácia deste procedimento à qualificação do entrevistador. A entrevista é um dos pontos, e o principal, obviamente, do DE. No entanto, esse procedimento envolve um conjunto complexo de ações, que envolve diferentes atores deste Sistema. É importante compreender que o DE vai além da entrevista propriamente dita, incluindo 
procedimentos que acontecem antes, durante e depois da audiência com a criança. Dessa forma, buscando explorar os desafios da interdisciplinaridade entre Psicologia, Serviço Social e Direito no DE, este estudo teve por objetivo construir um instrumento de avaliação da efetivação da Lei 13.431/2017 no que diz respeito especificamente à implementação do DE nas comarcas brasileiras.

\section{MÉTODO}

A construção do instrumento de avaliação envolveu as seguintes etapas: IRealização de estudo qualitativo para conhecer os aspectos que possibilitam e dificultam a efetivação do DE nas comarcas brasileiras; II-Construção dos itens e das escalas de respostas, com base na literatura e nos conteúdos emergidos na etapa I; III- Estruturação e organização do instrumento; e IV- Estudo de Validade de conteúdo (Coluci, Alexandre \& Milani, 2015).

A Etapa I envolveu revisão da literatura e coleta de dados por meio de um estudo exploratório descritivo, de caráter qualitativo, a partir de um survey online, com amostra não probabilística, buscando abordar as experiências profissionais de entrevistadores forenses. A pesquisa qualitativa pode ser considerada como uma tentativa de capturar a interpretação, uma exploração, elaboração e sistematização dos significados de um determinado fenômeno ou ainda uma representação que elucida o significado de um assunto ou problema delimitado. Nesta etapa, entrevistadores forenses, psicólogos e assistentes sociais, foram convidados a responder um questionário online com perguntas fechadas e abertas a respeito de suas experiências profissionais. Os critérios de inclusão na amostra eram: ter experiência em atuação em pelo menos dois processos judiciais como entrevistadores forenses em $\mathrm{DE}$, e possuir vínculo ativo com o Conselho Regional de Psicologia ou com o Conselho Regional de Serviço Social. Participaram da etapa I 36 profissionais da Psicologia ( $n=21,58,3 \%)$ e do Serviço Social $(n=15,41,7 \%)$, do sexo feminino $(n=32,88,9 \%)$ e masculino $(n=4,11,1 \%)$, com idades entre 30 e 57 anos $(m=41,83$; $d p=7,94)$ e com tempo de formação entre 2 e 35 anos ( $m=17,44$, $d p=8,67$ ). Os participantes eram oriundos das cinco regiões brasileiras, especificamente de onze estados, sendo uma parcela significativa do Estado do Rio Grande do Sul ( $n=13,36,1 \%)$ e outra do Estado de São Paulo ( $n=7,19,4 \%)$. Esses profissionais atuavam como entrevistadores no DE por um período entre menos de um ano e mais de 15 anos $(m=3,83 ; d p=3,15)$, indicando diferentes níveis de experiência nesta atividade. Diferentes níveis de escolaridade também caracterizaram a amostra, sendo que $11,1 \%$ tinham o Ensino superior completo $(n=4), 52,8 \%$ tinham Especialização $(n=19), 27,8 \%(n=10)$ Mestrado e 8,3\% $(n=3)$ Doutorado.

Todos os participantes foram capacitados para a atuação nesta atividade e a maior parte recebeu treinamento por meio do Tribunal de Justiça em que atua $(n=28$, $77,8 \%$ ), sendo que o restante teve capacitação por outros meios, incluindo recursos próprios ( $n=8,22,2 \%$ ). Os magistrados com quem esses profissionais trabalham receberam capacitação em $47,2 \%$ dos casos $(n=17)$. No restante dos casos, $25 \%$ 
dos magistrados não receberam treinamento $(n=9)$ e $27,8 \%$ não sabia responder se o magistrado com quem trabalhava recebeu ou não capacitação específica $(n=10)$.

Foi utilizado um questionário online, elaborado para este estudo, para investigar as percepções dos participantes sobre a atuação interdisciplinar no $D E$, a partir de sua experiência. As questões referiam-se a diferentes etapas do procedimento de escuta de crianças na esfera judicial, desde ações que ocorrem antes da audiência propriamente dita até outras que ocorrem depois da audiência. O instrumento foi disponibilizado online através da Plataforma Google Docs e os participantes foram convidados mediante um procedimento de Snow Ball. A plataforma ficou online, para coleta de dados, pelo período de dois meses, entre os meses de março e maio do ano de 2019. Foi utilizado o Termo de Consentimento Livre e Esclarecido - TCLE, demonstrando uma visão de um sujeito autônomo e com direito de conhecer objetivos, procedimentos, riscos e benefícios da pesquisa da qual está participando, segundo os preceitos do Conselho Nacional de Saúde (2016) e do Código de Ética Profissional do Psicólogo (Conselho Federal de Psicologia, 2005). Os dados foram submetidos a diferentes análises. Variáveis como sexo, idade, escolaridade e as respostas às questões fechadas foram analisadas quantitativamente, a partir de estatísticas descritivas rodadas por meio do Statistical Package for the Social Sciences - SPSS20. A análise das respostas às questões abertas envolveu análise de conteúdo (Bardin, 1977), com formulação de categorias a posteriori, a partir de três fases fundamentais: pré-análise, exploração do material e tratamento dos resultados (Bardin, 1977).

Na Etapa II, ocorreu a construção dos itens e das escalas de resposta. A revisão da literatura e os aspectos que emergiram das análises da primeira etapa serviram de base para a elaboração da primeira versão do instrumento. Conforme Coluci, Alexandre e Milani (2015), os itens de uma escala não podem ser construídos ao acaso e devem ser elaborados em função das definições operacionais do construto conforme desenvolvidos na etapa anterior. A experiência da população alvo é considerada uma excelente fonte de itens pelos autores citados. Na Etapa III, o instrumento foi consolidado a partir da: organização de seus itens em dimensões que se referiam ao momento específico do DE a ser avaliado (antes da audiência, durante e depois); elaboração de um título, instruções e escalas de respostas. Além disso, nesta etapa, os itens foram organizados em uma ordem lógica (Coluci, Alexandre \& Milani, 2015).

Na Etapa IV, procedeu-se a avaliação do conteúdo por dois juízes qualificados e conhecedores teóricos e práticos do DE. A avaliação ocorreu em uma etapa, em que os juízes verificaram se o conteúdo estava adequado aos respondentes, avaliaram a estrutura do instrumento proposto e se o conteúdo era representativo e suficiente. Nesta etapa, os juízes também puderam avaliar a adequação das escalas de resposta, sugerir novos itens, avaliar a clareza deles e das instruções do instrumento. 


\section{RESULTADOS}

Na etapa I, as categorias obtidas a posteriori, a partir da análise de conteúdo (Bardin, 1977) das respostas às questões abertas do questionário, realizada por juízes independentes, foram: Gestão do trabalho, Aspectos Técnicos e Necessidade de aperfeiçoamento.

\section{GESTÃO DO TRABALHO}

Dentre os aspectos de gestão do trabalho, os participantes indicaram que o agendamento prévio do DE pelo magistrado que considera a disponibilidade do entrevistador e realizado por uma central ou pela direção do Foro facilita o trabalho enquanto quando o agendamento feito de forma unilateral pelo magistrado, sem considerar a agenda do técnico entrevistador dificulta o trabalho e se caracteriza como um desrespeito a este profissional. A consulta aos autos, na sua íntegra, com os documentos que são relevantes para a compreensão da situação é apontada como fundamental pelos participantes, enquanto alguns técnicos indicam que levam muito tempo para conseguir acessar as informações de que necessitam, pois não há autorização prévia no despacho judicial. Outros aspectos associados a dificuldades no trabalho envolvem o cancelamento de audiências sem avisar o entrevistador ou as vítimas; atrasos no início da audiência; ocorrência de audiências sem uma duração apropriada e em quantidade que prejudica o desempenho do entrevistador ("depoimentos em série"). Um participante apontou que o magistrado com que trabalha tem "pressa" e busca realizar várias audiências no mesmo dia.

Outros aspectos observados referem-se à estrutura e à quantidade e qualificação dos recursos humanos. Com relação à estrutura, os participantes apontaram que a existência de salas e de equipamentos adequados possibilita que o trabalho ocorra de forma satisfatória, enquanto a falta dessa estrutura e também a falta de checagem dos equipamentos podem trazer dificuldades ou impedir a realização de audiências, frustrando-as. Os participantes indicaram que a falta de profissionais e a sobrecarga de trabalho bem como o acúmulo de funções dificultam a efetivação da Lei 13.431/2017. Destacaram ainda que algumas atividades são realizadas por estagiários e a rotatividade deles pode trazer prejuízos à realização do DE. Sobre os recursos humanos, houve ênfase na necessidade de qualificação por parte dos magistrados e de melhor entendimento dos demais operadores do Direito a respeito do procedimento e das necessidades e peculiaridades da escuta da criança. O diálogo, colaboração e respeito à interdisciplinaridade foram citados como facilitadores.

Os participantes destacaram ainda que a existência de um fluxo por meio de um protocolo administrativo que estabeleça uma organização dos diferentes setores envolvidos no DE facilita o trabalho, uma vez que cada profissional que atua neste sistema pode atuar de modo a proteger a vítima, desde antes de ela chegar ao Foro (como na intimação) até sua chegada e saída. Os profissionais entendem que é importante que a rede de proteção e justiça tenha um protocolo de atuação que englobe os diferentes momentos em que a vítima ou testemunha é ouvida, desde 
a denúncia até etapas posteriores ao DE. Neste protocolo/fluxo, deverá ser observado o tempo entre o fato e a condução do $D E$, o que deve ser breve e ágil; e também os cuidados com o entorno do depoimento. Os profissionais ainda entendem que os estudos psicossociais ou psicológicos devem ser preservados neste fluxo, a fim de que seja contextualizada a violência relatada pela criança e compreendida de um modo mais abrangente.

\section{ASPECTOS TÉCNICOS}

Com relação às questões técnicas do $\mathrm{DE}$, os participantes citaram aspectos que dificultam a aplicação de um protocolo de entrevista, como prevê a legislação atual. Alguns fatores apontados pelos participantes incluem a falta de confiança por parte de alguns operadores do Direito, na ciência psicológica. Exemplificam que durante a audiência ocorrem interrupções, inclusive em meio ao relato livre da criança/adolescente; sugestões para que o entrevistador realize o DE de maneira diversa; solicitações de agilidade e objetividade durante o DE. Além disso, os participantes referem que ocorrem perguntas sobre detalhes do evento sofrido pela criança; insistência em perguntas que a criança/adolescente não respondeu como os "operadores do Direito esperavam" (sic); solicitações de informações que o entrevistado já relatou porque os "operadores não prestaram a atenção devida" ("estavam no celular ou em conversas paralelas" sic), além de solicitação de informações consideradas inadequadas (como se o pênis do acusado estava ereto) ou que culpabilizam a vítima. Uma participante revelou que uma magistrada exigiu que ela utilizasse o ponto durante toda a entrevista e que ela repetisse apenas o que foi perguntado.

Por outro lado, os participantes indicaram que quando existe autonomia técnica e quando o magistrado tem confiança no entrevistador e em suas habilidades, ele não interfere no trabalho e possibilita o uso do protocolo da maneira adequada. Nestes casos, os entrevistadores referiram que há respeito às etapas do protocolo utilizado e, portanto, há respeito ao tempo necessário, e consequentemente, à vítima/testemunha. Ainda, quando o magistrado apresenta uma postura proativa de indeferir perguntas inadequadas, ofensivas, constrangedoras e repetidas, facilita o trabalho técnico no DE. A "parceria com o juiz" (sic), o contato prévio, o diálogo e o feedback também foram apontados como fatores que contribuem para o $D E$.

\section{NECESSIDADE DE APERFEIÇOAMENTO}

Dentre as necessidades de aperfeiçoamento citadas pelos participantes, estão a qualificação, a realização de estudos, pesquisas e eventos sobre o tema e outros aspectos gerais. A qualificação de todos os profissionais é compreendida como uma necessidade da área. Não apenas daqueles que conduzem a entrevista, mas também dos operadores do Direito, como magistrados, promotores de justiça e os defensores/advogados. Há indicação de que oficiais de justiça também sejam capacitados, devido ao seu trabalho de intimação das vítimas e famílias; assim como os servidores do cartório e do gabinete do magistrado. Os participantes entendem que a qualificação deve envolver conteúdos sobre técnicas de 
entrevista, e aspectos da violência contra crianças e adolescentes, do desenvolvimento infantil e cognitivo, incluindo funcionamento da memória. Ainda, compreendem que a qualificação deveria ser obrigatória, constante e continuada, pelo menos em varas especializadas que atuam com o tema diariamente. Especificamente em relação aos entrevistadores, a sugestão é de que realizem supervisão regular e constante, de modo a qualificar sua atuação.

Os participantes entendem como relevante a realização de estudos sobre as práticas em $D E$, incluindo as vivências e sentimentos relacionados ao $D E$ pela criança/adolescente e familiares e suas avaliações após o DE. Os participantes indicam também a necessidade de realização de eventos anuais em nível nacional, que possam abordar os avanços, os desafios e a avaliação da implantação da lei, assim como troca de experiências entre as comarcas. Por fim, os participantes apontam que há necessidade de melhoria nos equipamentos, espaços físicos e também o aumento dos recursos humanos envolvidos, com ampliação do número de técnicos entrevistadores. Estes técnicos, segundo os entrevistados, deveriam ser de equipes fixas, evitando a rotatividade de profissionais, de modo que pudesse ser construída uma relação de confiança na condução dos depoimentos.

Considerando as categorias de análise emergidas, observa-se que o DE deve ser compreendido de forma ampla, englobando diferentes aspectos e atores do Sistema de Justiça, que vão além da entrevista com a criança. Os dados levantados pelos entrevistadores forenses neste estudo demonstraram que o DE não pode ser reduzido à análise da entrevista a ser conduzida por um determinado profissional, mas deve ser observado em todos os seus momentos, desde a organização administrativa e estrutural até os encaminhamentos realizados, passando pela qualificação de todos os profissionais envolvidos.

Após as Etapas II e III, de construção dos itens e organização, a primeira versão do instrumento contava com 31 itens, divididos nas seções Antes, Durante e Depois da audiência. Na seção "Antes da audiência", constam itens incluindo o agendamento do DE e determinações judiciais prévias, a existência de fluxos e estrutura na comarca, a qualificação do magistrado e do entrevistador. Na seção "Durante a audiência", constam itens incluindo a avaliação da condução da audiência pelo magistrado e da entrevista pelo entrevistador. Na seção "Depois da audiência", constam itens sobre a avaliação da criança sobre sua participação, se havia discussão de caso entre magistrado e entrevistador, encaminhamentos e supervisão.

$\mathrm{Na}$ etapa IV, dois juízes qualificados e conhecedores teóricos e práticos do DE verificaram o conteúdo dos itens e a estrutura do instrumento. Nesta etapa, os juízes também puderam avaliar a adequação das escalas de resposta, sugerir novos itens, avaliar a clareza das questões e das instruções do instrumento. As sugestões dos juízes foram incorporadas, sendo que alguns itens foram subdivididos para que pudessem avaliar mais especificamente alguns aspectos (Ex.: $\mathrm{O}$ item "O juiz indefere questões inadequadas à criança/adolescente, de modo a protegê-la de 
eventual revitimização" deu origem a quatro itens na versão final do instrumento, a saber, itens 26, 27, 28 e 29). Ainda, foram realizadas alterações na escrita de alguns deles, com o objetivo de alcançar maior clareza e compreensão (Ex.: o item original "O tempo entre os fatos narrados e o DE é breve?" deu origem ao item 17, que oferece períodos de tempo específicos para o respondente e evita a subjetividade da palavra "breve"). Outra importante alteração trazida pelos juízes foi no ajuste das escalas de resposta, que se tornaram específicas de acordo com o tipo de questionamento. A primeira versão propunha apenas respostas do tipo Sim/Não, com possibilidade de o respondente inserir observações e comentários qualitativos em cada item. Na versão final do instrumento alguns itens são respondidos a partir de Escala Likert e outros com resposta dicotômica Sim/Não, dependendo do tipo de informação solicitada, tendo sido mantido o espaço de comentários e observações. Após a realização dos ajustes indicados, a versão final do instrumento ficou composta por 50 itens em formato de questões, distribuídas de acordo com os momentos do DE (antes, durante e após) e com escalas específicas de respostas.

A versão final do instrumento está apresentada como anexo neste artigo. O objetivo deste instrumento é contribuir na avaliação da implementação do DE nas comarcas brasileiras, considerando todos os aspectos que a atividade envolve, de modo que se possa identificar também, pontos de fragilidade que indiquem as necessidades de qualificação, mudanças e investimentos específicos. O instrumento deve ser respondido por gestores, equipes técnicas ou equipes de trabalho interdisciplinar, preferencialmente de forma coletiva, de modo que possibilite um debate sobre as forças e fraquezas da comarca em relação à efetivação da Lei 13.431/2017.

\section{DISCUSSÃO E CONSIDERAÇõES FINAIS}

O presente estudo possibilitou a construção de um instrumento para avaliar as condições de implementação do DE no Brasil, de modo a contribuir para a identificação das forças e fraquezas do trabalho de cada comarca. Como se percebe diante dos resultados das análises qualitativas e da própria configuração do instrumento, a efetivação da lei depende, portanto, não apenas dos entrevistadores estarem qualificados para a aplicação de protocolos, mas de um conjunto ampliado de ações e de recursos. Antes da audiência, aspectos como o agendamento, a existência de fluxos e estrutura física e de recursos humanos, além da qualificação de magistrados e servidores compõem o cenário onde ocorrerá o DE. Durante a audiência, destacam-se a pontualidade da audiência, bem como ações específicas do magistrado que a conduz e os aspectos técnicos, que envolvem a possibilidade de aplicação de um protocolo sem interferências. Por fim, depois da audiência, é importante observar a avaliação da própria criança sobre sua participação, bem como a presença de discussão de caso, encaminhamentos, supervisão e ações de qualificação continuada. 
Silva e colaboradores (2013) em pesquisa realizada com 10 membros do Poder Judiciário que atuavam numa central de depoimentos identificaram desafios e necessidades do trabalho neste contexto. Apontam que são necessárias adaptações em diferentes esferas, como pessoal, social e institucional para que o projeto de colher depoimentos de crianças e adolescentes de forma especial seja efetivado. Os autores abordam a questão da estrutura física, a dinâmica existente e a morosidade dos trâmites processuais, mencionando que a realidade institucional fere o princípio da proteção integral da criança e do adolescente. Ainda, os autores observam que a necessidade de relações articuladas e de "sintonia" entre as equipes de trabalho, bem como de que haja investimentos semelhantes no sentido de minimizar os danos decorrentes da violência, não devendo a atuação do Sistema de Justiça ser limitado à responsabilização do agressor. Os resultados de Silva e colaboradores (2013) e os desta pesquisa indicam que amplos ajustes e investimentos ainda precisam ser feitos no contexto brasileiro para que seja garantido o mínimo necessário para a real efetivação da Lei.

As práticas mais recentes de escuta da criança no Poder Judiciário são, no entendimento de Froner e Ramires (2008), visivelmente mais adequadas ao universo infantil quando comparadas às antigas práticas, pois apresentam um acolhimento mais humanizado. Neste contexto de trabalho, segundo as autoras, o profissional da saúde é considerado um parceiro importante na escuta da criança no Judiciário, pois poderá avaliar suas condições, aliviar angústias e contribuir para não causar outras, pode atuar como agente facilitador da fala e das emoções da criança, preparar a criança para a escuta, amenizar seus medos e crenças, eliminar a desorientação e confusão que o Sistema Legal pode produzir e orientar sobre os procedimentos que ela precisa enfrentar. As autoras ressaltam, entretanto, a importância do trabalho interdisciplinar para a proteção dos direitos da criança e para a devida atenção a seu estado subjetivo diante da experiência traumática. Ressalta-se também que a Lei 13.431/2017 não determina que profissionais podem ou devem realizar a entrevista forense, mas indica que deve ser conduzida por profissional especializado (Brasil, 2017), o que potencializa a característica interdisciplinar desse procedimento de escuta.

A literatura tem apontado ainda que a necessidade de qualificação ultrapassa a formação universitária e deve envolver uma capacitação continuada tanto para os profissionais entrevistadores quanto para os operadores do Direito. Para Froner e Ramires (2009), os primeiros devem conhecer melhor o Estatuto da Criança e do Adolescente - ECA para compreender quais são os direitos da criança e de que forma eles podem beneficiá-la; e os operadores necessitam conhecer mais sobre o modo de funcionar da criança. Formação continuada, treinamentos frequentes e supervisão psicológica foram estratégias apontadas para o caminho da qualificação técnica (Silva, Ferriani, Beserra, Roque, \& Carlos, 2013).

Na etapa 1 deste estudo, identificou-se que a gestão do trabalho no DE deve envolver ações que tornem fluido o trabalho do entrevistador, como o agendamento dos depoimentos conforme sua disponibilidade e também em um 
número máximo por turno. A pontualidade das audiências, a disponibilização prévia dos autos ao entrevistador e a comunicação entre ele e o magistrado também foram citadas como questões primordiais para a qualidade do trabalho. Salas e equipamentos adequados, recursos humanos em quantidades suficiente, bem como a existência de um fluxo prévio de sistematização do DE foram também citados como parte da gestão do DE. Entre os aspectos técnicos, os participantes destacaram a possibilidade de condução integral de um determinado protocolo de entrevista, contando com a confiança do magistrado, com sua não interrupção e com o indeferimento, por parte dele, de questões que são consideradas inadequadas e/ou culpabilizantes. Por fim, a necessidade de qualificação envolve tanto a capacitação destes diferentes atores (entrevistadores e operadores do Direito) quanto a realização de estudos, pesquisas e eventos que tratem desta temática.

A versão final do instrumento construído a partir deste estudo buscou incluir todos os aspectos identificados como importantes na realização do $D E$, tanto a partir da literatura existente, quanto da percepção dos profissionais com experiência relevante nesta prática. A construção do instrumento seguiu as diretrizes recomendadas, de maneira que o objetivo do trabalho foi o de oferecer um recurso consistente para a avaliação da implementação do DE nas comarcas brasileiras. O instrumento pode ser utilizado pelas comarcas de maneira autônoma, a partir de uma autoavaliação, e também pode ser utilizado por pesquisadores e corregedorias de justiça para a avaliação externa das comarcas. Sempre no sentido de identificar forças e fraquezas e possibilitar o investimento nas reais necessidades das comarcas, este instrumento objetiva contribuir para a efetivação da Lei 13.431/2017 no Brasil, no que diz respeito especificamente ao DE.

Dentre as limitações deste estudo, além da quantidade de entrevistadores forenses participantes da Etapa I, aponta-se a necessidade de realização de uma etapa posterior, de pré teste do instrumento, conforme orientam Coluci, Alexandre e Milani (2015). O instrumento apresentado neste trabalho foi construído com o propósito de auxiliar na organização das comarcas brasileiras, tanto em termos práticos quanto em termos de entendimento da complexidade deste procedimento, que envolve diferentes ações e atores. Não é possível efetivar a lei que busca a proteção da criança vítima e testemunha de violência no Brasil sem que exista um olhar ampliado sobre as necessidades do Sistema de Justiça. As responsabilidades não recaem unicamente sobre o profissional entrevistador, mas devem ser compartilhadas com outros profissionais e principalmente, com as instituições, que devem garantir as estruturas necessárias e fundamentais para a prática do DE no país. As mudanças paradigmáticas exigem tempo, mas estão ocorrendo no Sistema de Justiça brasileiro, que recorre aos conhecimentos e técnicas de outras disciplinas para melhor atuar na proteção das crianças e adolescentes. 


\section{REFERÊNCIAS}

Alves Júnior, R. T. (2013). Um sistema de análise de entrevistas forenses com crianças em casos de suspeita de abuso sexual (Tese de Doutorado, Programa de Pós-Graduação em Psicologia Clínica e Cultura, Universidade de Brasília).

Aznar-Blefari, C., \& Padilha, M. D. G. S. (2015). Capacitação para o uso do Protocolo NICHD em profissionais sul-brasileiros. Revista de Psicología, 24(1), 1-19. http://dx.doi.org/10.5354/0719-0581.2015.37198

Bardin, L. (1977). Análise de conteúdo. Lisboa: Edições 70.

Brasil (2017). Lei n. 13.431, de 4 de abril de 2017. Retirado de http://www.planalto.gov.br/ccivil_03/_ato2015-2018/2017/lei/L13431.htm

Brasil (2018). Decreto 9.603, de 10 de dezembro de 2018. Retirado de http://www.planalto.gov.br/ccivil_03/_Ato2015-2018/2018/Decreto/D9603.htm

Brito, L. M. T. de, \& Parente, D. C. (2012). Inquirição judicial de crianças: pontos e contrapontos. Psicologia \& Sociedade, 24(1), 178-186.

Childhood Brasil, Conselho Nacional de Justiça, Funda das Nações Unidas para a Infância \& National Children's Advocacy Center (2020). Protocolo Brasileiro de Entrevista forense com crianças e adolescentes vítimas e testemunhas de violência. São Paulo e Brasília: Childhood - Instituto WCF Brasil, CNJ, UNICEF.

Coluci, M. Z. O., Alexandre, N. M. C., \& Milani, D. (2015). Construção de instrumentos de medida na área da saúde. Ciência \& Saúde Coletiva, 20(3), 925-936. https://doi.org/10.1590/141381232015203.04332013

Conselho Federal de Psicologia (2005). Código de ética profissional do psicólogo. Brasília: Conselho Federal de Psicologia. Retirado de https://site.cfp.org.br/wpcontent/uploads/2012/07/codigo-de-etica-psicologia.pdf

Conselho Nacional de Justiça - CNJ (2010). Recomendação 33/2010. Retirado de https://atos.cnj.jus.br/atos/detalhar/atos-normativos?documento=878 em 17 de dezembro de 2019.

Conselho Nacional de Justiça - CNJ (2019). Resolução 299/2019. Retirado de https://atos.cnj.jus.br/atos/detalhar/3110 em 17 de dezembro de 2019.

Conselho Nacional de Saúde (2016). Resolução 510/2016. Dispõe sobre as normas aplicáveis a pesquisas em Ciências Humanas e Sociais. Disponível em www.conselho.saude.gov.br em 30 de junho de 2018.

Daltoé Cézar J. A. (2007). Depoimento Sem Dano: Uma alternativa para inquirir crianças e adolescentes nos processos judiciais. Porto Alegre, RS: Livraria do Advogado.

Dobke, V. (2001). Abuso sexual: a inquirição das crianças - uma abordagem interdisciplinar. Porto Alegre: Ricardo Lenz Editor.

Froner, J. P. \& Ramires, V. R. R. (2008). Escuta de crianças vítimas de abuso sexual no âmbito jurídico: Uma revisão crítica da literatura. Paideia, 18(40), 267-278. https://doi.org/10.1590/S0103863X2008000200005

Froner, J. P. \& Ramires, V. R. R. (2009). A escuta de crianças vítimas de abuso sexual intrafamiliar na concepção de profissionais que atuam no âmbito do Judiciário. Psicologia em Revista, 15(3), 60-81. https://doi.org/10.5752/P.1678-9563.2009v15n3p60

Pelisoli, C., \& Dell'aglio, D. D. (2016). A humanização do sistema de justiça por meio do Depoimento Especial: Experiências e desafios. Psico USF, 21(2), 409-421. https://doi.org/10.1590/141382712016210216

Potter, L. (Org.). (2010). Depoimento sem Dano: Uma Política Criminal de Redução de Danos. Rio de Janeiro: Lumen Juris.

Roque, E. M. S. T., Ferriani, M. G. C., Gomes, R., Silva, L. M. P., \& Carlos, D. M. (2014). Sistemas de justiça e a vitimização secundária de crianças e ou adolescentes acometidas de violência sexual intrafamiliar. Saúde e Sociedade, 23(3), 801-813. https://doi.org/10.1590/S010412902014000300006

Sadek, M. T. (2010). O sistema de justiça [online]. Rio de Janeiro: Centro Edelstein de Pesquisas Sociais.

Santos, B. R., Gonçalves, I. B., Vasconcelos, M. G. O. M., Barbieri, P. B. \& Viana, V. N. (2014). Escuta de crianças e adolescentes em situação de violência sexual Aspectos Teóricos e Metodológicos: Guia para capacitação em Depoimento Especial de Crianças e Adolescentes. Brasília-DF: Universidade Católica de Brasília. 
Sanson, J. A. S. \& Von Hohendorff, J. (2021). Depoimento Especial a partir de opiniões de psicólogos brasileiros atuantes nessa prática. Psico USF, 26(1), 27-39. https://doi.org/10.1590/141382712021260103

Silva, L. M. P. S., Ferriani, M. G. C. Beserra, M. A., Roque, E. M. S. T., \& Carlos, D. M. (2013). A escuta de crianças e adolescentes nos processos crime. Ciência \& Saúde Coletiva, 18(8), 2285-2294. https://doi.org/10.1590/S1413-81232013000800012

Williams, L. C. A., Hackbarth, C., Blefari, C. A., Padilha, M. G. S., \& Peixoto, C. E. (2014). Investigação de suspeita de abuso sexual infantojuvenil: o Protocolo NICHD. Temas em Psicologia, 22(2), 415432. http://dx.doi.org/10.9788/TP2014.2-12

\section{AGRADECIMENTOS}

As autoras agradecem aos entrevistadores forenses participantes da pesquisa e aos juízes independentes que contribuíram para a construção do instrumento.

\section{CONFLITOS DE INTERESSES}

Não há conflitos de interesses.

\section{SOBRE OS AUTORES}

Cátula da Luz Pelisoli é Doutora em Psicologia e Psicóloga Judiciária do Tribunal de Justiça do Estado do Rio Grande do Sul.

E-mail: catulapelisolil@yahoo.com.br

(1) https://orcid.org/0000-0002-7228-0449

Débora Dalbosco Dell'Aglio é Doutora em Psicologia, Professora Pesquisadora do Programa de Pós Graduação em Educação da Universidade La Salle e Professora Colaboradora do Programa de Pós Graduação em Psicologia da Universidade Federal do Rio Grande do Sul.

E-mail: dddellaglio@gmail.com

(1) https://orcid.org/0000-0003-0149-6450 


\section{Check List para avaliação da implementação do Depoimento Especial - Cátula da Luz Pelisoli \& Débora Dalbosco Dell'Aglio, 2021}

Este instrumento foi desenvolvido para a avaliação de diferentes fatores que compõem a estrutura necessária para a realização do Depoimento Especial nas comarcas brasileiras, buscando realizar diagnósticos institucionais em relação à efetivação da Lei 13.431/2017, com vistas à identificação das potencialidades e necessidades de cada local. Este instrumento deve ser utilizado por pesquisadores, gestores ou equipes, por profissionais diretamente envolvidos nos Depoimentos Especiais nas comarcas. Sugere-se que seja respondido coletivamente pela equipe responsável. As questões deverão ser respondidas conforme a indicação em cada sessão. Em todas as questões, é possível realizar observações, que poderão contribuir para a maior compreensão da necessidade da comarca, e quando alguma questão não estiver prevista na condução dos Depoimentos Especiais na sua comarca poderá indicar-se na seção de observação a expressão "Não se aplica". Algumas perguntas exigem uma resposta do tipo Sim/Não e outras devem ser respondidas conforme a Escala abaixo:

1) Nunca

2) Na minoria das vezes

3) Regularmente

4) Na maioria das vezes

5) Sempre

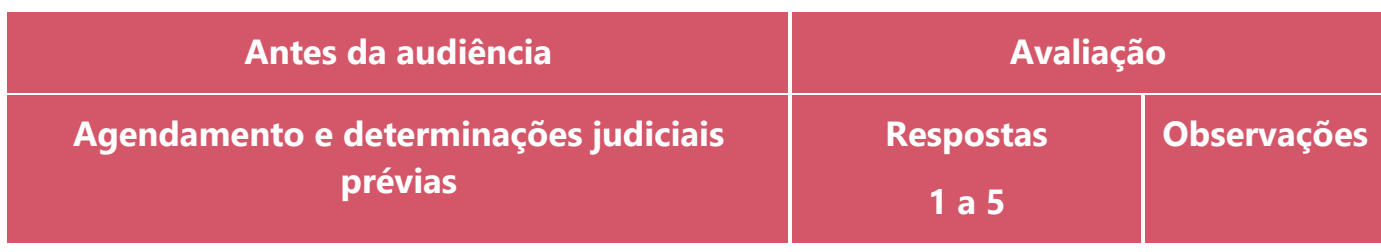

1. O agendamento é realizado considerando a disponibilidade do entrevistador?

2. O agendamento é feito por uma central ou pela direção do Foro, dispensando o entrevistador desta atividade administrativa?

3. O agendamento considera o tempo mínimo de uma hora para cada criança/adolescente a ser ouvido?

4. O agendamento considera um número máximo de depoimentos por turno para cada entrevistador (3 no turno da manhã e 4 no turno da tarde)? 
5. Há determinação judicial prévia autorizando a carga dos autos ao entrevistador ou o envio dos

materiais necessários ao entrevistador?

6. Os autos são disponibilizados ao

entrevistador com antecedência mínima de 15

dias da data da audiência?

7. A vítima/testemunha é intimada em tempo hábil, considerando um prazo mínimo de pelo menos 15 dias da data da audiência?

\section{Fluxos e estrutura:}

8. De modo geral, há estrutura física na Comarca que dê garantia suficiente de que vítima e suposto agressor não se encontrem (para esta resposta, considere o prédio do Fórum como um todo)?

9. Especificamente, a sala de recepção é adequada em termos de proteção, evitando o contato entre vítima e réu e entre vítima e possíveis representantes do réu que possam causar desconforto à criança/adolescente?

10. A sala de recepção possui mobiliário que denote conforto e acolhimento ao entrevistado?

11. A sala de entrevista possui isolamento acústico e/ou garante a privacidade do entrevistado?

12. A sala de entrevista possui mobiliário que denote conforto e acolhimento ao entrevistado?

13. A sala de entrevista é adequada em termos de evitar estímulos em demasia (brinquedos visíveis, poluição visual, etc)?

14. Os equipamentos (áudio e vídeo) são adequados às necessidades do DE?

15. Os equipamentos (áudio e vídeo) são checados com antecedência?

16. Há um fluxo organizado prévio que envolve os diferentes setores, como gabinete, cartório e setor técnico para a realização do DE?

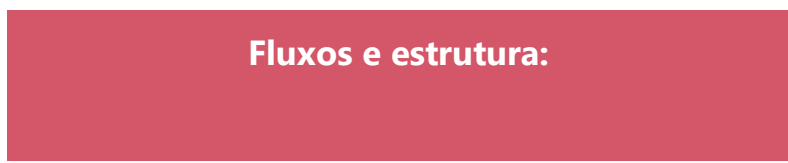

17. O tempo entre os fatos descritos no processo judicial (considerando boletim de ocorrência policial) e o DE da vítima/testemunha é, na maioria dos casos:
Respostas

\section{1 a 5}

1)Menos de seis meses do evento

2) Entre seis meses e um ano do evento 
3) Entre um e dois anos do evento

4) Entre dois e três anos do evento

5) Mais de três anos depois do evento

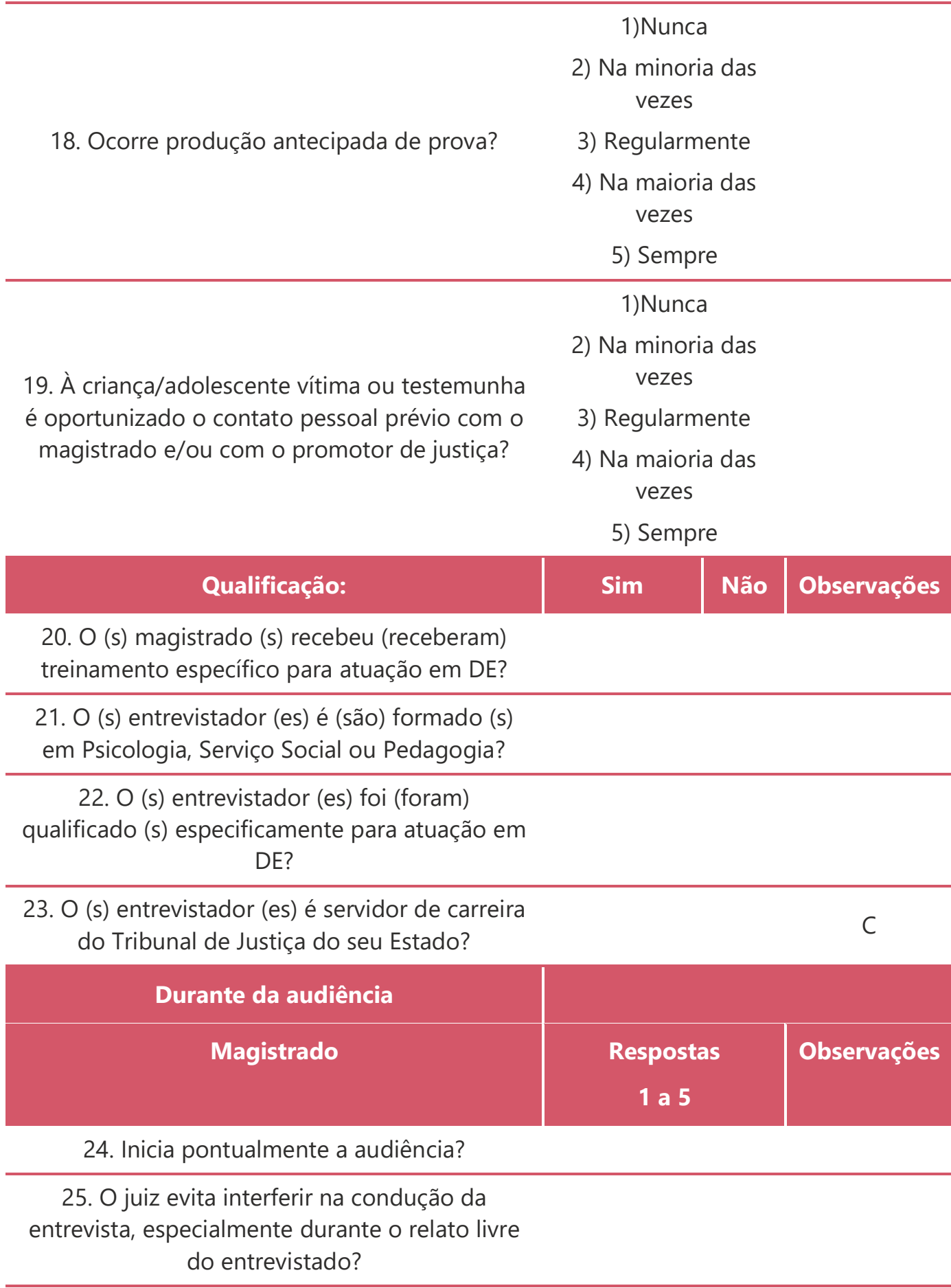

26. De um modo geral, o juiz indefere questões inadequadas à criança/adolescente, de modo a protegê-la de eventual revitimização? 
27. O juiz indefere questões que abordam a vida sexual de um(a) adolescente, que não diz respeito ao objeto processual, de modo a protegê-la de eventual revitimização?

28. O juiz indefere questões que repetem informações que já foram colocadas pelo entrevistado, de modo a protegê-lo de eventual revitimização?

29. O juiz indefere questões que geram responsabilização e sentimentos de culpa no entrevistado, de modo a protegê-lo de eventual revitimização?

30. De um modo geral, o juiz respeita a autonomia do entrevistador para a condução do $D E$ ?

31. O juiz acolhe a manifestação do entrevistador quando este informa que uma determinada pergunta pode ser revitimizante?

32. O juiz acolhe a manifestação do entrevistador quanto à presença do acusado na sala de audiências?

33. O juiz acolhe a manifestação do entrevistador no que diz respeito a indicações de medidas de proteção necessárias?

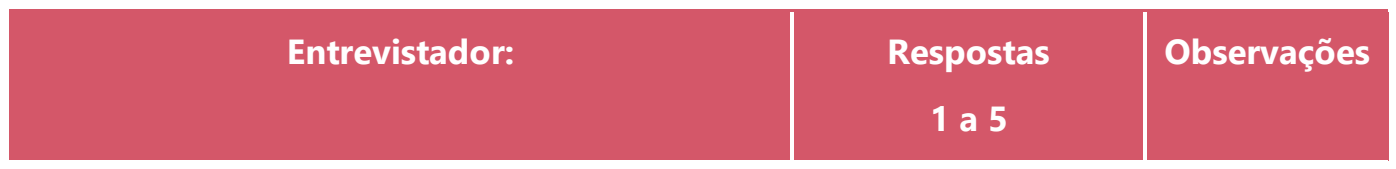

34. O entrevistador segue um protocolo de entrevista reconhecido?

35. Respeita o tempo e os silêncios da criança?

36. O entrevistador utiliza linguagem adequada à criança, de modo que seja compreensível e acessível segundo a faixa etária da vítima/testemunha?

37. Durante o relato livre do entrevistado, o entrevistador evita fazer perguntas fechadas e/ou sugestivas (que forneçam informações sobre o conteúdo processual?

38. Apresenta postura e tom de voz acolhedor?

39. Ao final da entrevista, o entrevistador pergunta se a criança quer falar mais alguma coisa?

40. Ao final da entrevista, o entrevistador direciona a questões emocionalmente neutras? 
41. Ao final da entrevista, o entrevistador pergunta à criança como se sentiu?

42. Ao final da entrevista, o entrevistador agradece a criança?

43. O entrevistador faz encaminhamentos para atendimentos na rede de saúde e proteção quando considera necessário?

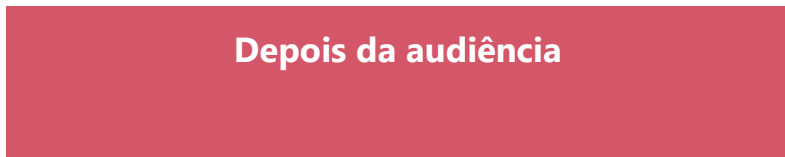

Respostas Observações

44. É colhida a avaliação/percepção da criança sobre sua participação no DE?

45. A avaliação da criança/adolescente a respeito de sua participação no DE é positiva?

46. Quando a avaliação da criança sobre sua participação no DE não é positiva, o entrevistador procura conhecer os motivos e identificar as alterações necessárias?

47. Há discussão de caso entre magistrado e entrevistador ou um contato/feedback entre eles sobre o funcionamento do DE após a audiência?

48. Há encaminhamento da criança/adolescente para a rede de atendimento ou verificação de atendimento já em andamento?

49. Há supervisão da entrevista realizada ou discussão do caso em equipe técnica?

50. Existem ações de qualificação continuada dos profissionais que estão envolvidos no DE (supervisão contínua, cursos, eventos)? 